\title{
Unemployment and health-related quality of life in melanoma patients during the COVID-19 pandemic: A web-based cross-sectional study
}

\section{Yeye Guo}

Xiangya Hospital Central South University

\section{Minxue Shen}

Xiangya Hospital Central South University

\section{Xu Zhang}

Xiangya Hospital Central South University

\section{Yi Xiao}

Xiangya Hospital Central South University

\section{Shuang Zhao}

Xiangya Hospital Central South University

\section{Mingzhu Yin}

Xiangya Hospital Central South University

\section{Wenbo Bu}

Chinese Academy of Medical Sciences \& Peking Union Medical College Hospital of Skin Diseases and Institute of Dermatology

\section{Yan Wang}

Chinese Academy of Medical Sciences \& Peking Union Medical College Hospital of Skin Diseases and Institute of Dermatology

\section{Xiang Chen}

Xiangya Hospital Central South University

Juan Su ( $\sim$ sujuanderm@csu.edu.cn )

Xiangya Hospital Central South University https://orcid.org/0000-0001-7035-2560

\section{Short report}

Keywords: melanoma, coronavirus disease 2019 , unemployment, health-related quality of life, a webbased survey

Posted Date: June 25th, 2020

DOI: https://doi.org/10.21203/rs.3.rs-37039/v1 
License: (c) (i) This work is licensed under a Creative Commons Attribution 4.0 International License. Read Full License 


\section{Abstract \\ Background}

The outbreak of coronavirus disease-2019 (COVID-19) ineluctably caused social distancing and unemployment, which may bring additional health risks for patients with cancer. To investigate the association of the pandemic-related impacts with the health-related quality of life (HRQOL) among patients with melanoma during the COVID-19 pandemic, we conducted a cross-sectional study among Chinese patients with melanoma.

\section{Methods}

A self-administered online questionnaire was distributed to melanoma patients through social media. Demographic and clinical data, and pandemic-related impacts (unemployment and income loss) were collected. HRQoL was determined by the Functional Assessment of Cancer Therapy-General (FACT-G) and its disease-specific module (the melanoma subscale, MS).

\section{Results}

A total of 70 patients with melanoma completed the study. The mean age of the patients was $55.2 \pm 14.8$ years, $45.7 \%$ (32/70) were male, and 21.4\% (15/70) were unemployed since the epidemic. Unemployment of the patients and their family members and income loss were significantly associated with a lower FACT-G score, while the MS score was associated with the unemployment of the patients' family members.

\section{Conclusions}

Our findings suggested that unemployment is associated with impaired HRQoL in melanoma patients during the COVID-19 epidemic.

\section{Background}

The outbreak and pandemic of the coronavirus disease 2019 (COVID-19) brought profound impacts on the entire society and the individual's life. Besides the confirmed and suspected cases in hospitals or health facilities, the majority of people started the self-isolation at home voluntarily. However, the lockdown resulted in income loss and unemployment in some people. Under the circumstances, patients with cancers or chronic conditions may face higher risks of job loss and more mental and physical stress.

Melanoma is the most serious type of skin cancers with a highly aggressive ability. The 5-year survival rate can be low as $5 \%$ for advanced melanoma [1], and the median overall survival time is about 
8 months [2]. Such poor survival outcomes result in heavy mental stress and impaired quality of life. Approximately one-third of patients with melanoma reported psychological distress to some extent, and symptoms of anxiety were more prevalent than depression [3]. Neoadjuvant therapy such as checkpoint therapy and target therapy has been rapidly developed in recent years, and significantly benefited melanoma patients. However, high medical costs imposed heavy financial burdens on these patients. It was estimated that over 25,000 US dollars were cost per person annually for patients in late stages [4]. As a result, unemployment and income loss may not only result in emotional problems but also lead to unaffordability during the advanced treatment for melanoma.

In the current study, we investigated the association of unemployment, income loss and other epidemicrelated impacts with the health-related quality of life (HRQoL) in melanoma patients in China, based on an online questionnaire survey.

\section{Methods}

A cross-sectional study among Chinese melanoma patients was conducted between 4 Apr, 2020 and 11 Apr, 2020. The online survey link to facilitate the collection of questionnaires was distributed on social media (WeChat groups and teledermatology platforms). Every single IP address was allowed only one entry and submission in order to avoid repeated submissions by individual patients. The final submission required the patients to complete all the questions. The study was reviewed and approved by the institutional research ethics boards of Xiangya Hospital, Central South University (approval number: 202002024). Electronic informed consent was collected from all participants before the survey.

The exposure variables (employment status, income change and outdoor activity restriction) and covariates (gender, age, educational level, annual income, marital status, clinical stage of melanoma, course of melanoma, site of melanoma, current status of disease, comorbidities, adherence to treatment, and healthcare utilization) were collected. Functional Assessment of Cancer Therapy-Melanoma (FACT$\mathrm{M})$, an outcome measurement system, was use to evaluate the quality of life in melanoma patients (www.facit.org). FACT-M is composed of a core questionnaire, the FACT-General (FACT-G), and a diseasespecific module including melanoma subscale (MS), and melanoma surgery scale (MSS) [5]. In our study, the primary outcome was the FACT-G score (the sum of physical well-being (PWB), social/family wellbeing (SWB), emotional well-being (EWB) and functional well-being (FWB)), and the secondary outcome was the MS score. The possible score ranges of the FACT-G and MS were 0-108 and 0-64, respectively, and higher scores indicate better HRQoL. The MSS was not analyzed since not all patients received surgery. The use of the FACT-M was authorized, and the Chinese version was obtained from the copyright holder before the survey.

\section{Statistical Analyses}

There was no missing data in the questionnaire survey. The data were exported from the online survey system and analyzed with $\mathrm{R}$ version 3.5.2. Continuous variables with normal distribution were expressed 
as mean \pm standard deviation (SD) and compared with analysis of variance (ANOVA). Hotelling's T2 test was used for the multivariate comparison of multiple subscale scores. Continuous data with skewed distribution were presented as median (interquartile range, IQR) and compared with Wilcoxon rank sum test. Categorical variables were summarized as counts (percentages) and compared using the chi-square test or Fisher's exact test. Stepwise linear regression with the corrected Akaike information criteria was used to identify variables that were associated with the outcomes. The effect size of the association was presented as regression coefficient and $95 \%$ confidence interval. P-value less than 0.05 was considered statistically significant. Reporting of the results followed the STROBE guideline.

\section{Results}

From April 4, 2020 to Apr 11, 2020, a total of 70 valid questionnaires was collected and analyzed. None reported confirmed infection with COVID-19. The mean age of the patients was $55.2 \pm 14.8$ years, and 32 (45.7\%) were male. The characteristics of participants by employment status were shown in Table 1. Educational level, marital status, history of hypertension, income change since the epidemic, and employment status of family members were significantly different across the groups. The intracluster correlation coefficients of the subscales of FACT-M varied from 0.82 to 0.92 , indicating good internal reliability. The mean FACT-G and MS scores were $72.1 \pm 17.1$ and $52.5 \pm 7.6$, respectively. 
Table 1

Demographic and clinical characteristics of the participants

\begin{tabular}{|c|c|c|c|c|c|}
\hline \multirow[t]{2}{*}{ Characteristics } & \multirow{2}{*}{$\begin{array}{l}\text { Total } \\
(\mathrm{N}= \\
70)\end{array}$} & \multicolumn{3}{|c|}{ Employment status } & \multirow[t]{2}{*}{$P$} \\
\hline & & $\begin{array}{l}\text { Unemployed } \\
\text { since the } \\
\text { epidemic }(n=15)\end{array}$ & $\begin{array}{l}\text { Unaffected since } \\
\text { the epidemic ( } \mathrm{n} \\
=30 \text { ) }\end{array}$ & $\begin{array}{l}\text { Unemployed before } \\
\text { the epidemic or retired } \\
(n=25)\end{array}$ & \\
\hline $\begin{array}{l}\text { Age (year), } \\
\text { mean } \pm S D^{\dagger}\end{array}$ & $\begin{array}{l}55.2 \\
\pm \\
14.8\end{array}$ & $48.6 \pm 12.2$ & $50.6 \pm 12.6$ & $64.7 \pm 14.3$ & \\
\hline Gender, \% & & & & & 0.436 \\
\hline Male & 45.7 & 33.3 & 53.3 & 44.0 & \\
\hline Female & 54.3 & 66.7 & 46.7 & 56.0 & \\
\hline $\begin{array}{l}\text { Educational } \\
\text { level, \% }\end{array}$ & & & & & $<.001$ \\
\hline $\begin{array}{l}\text { Primary school } \\
\text { and below }\end{array}$ & 18.6 & 20.0 & 6.7 & 32.0 & \\
\hline Middle school & 34.3 & 66.7 & 33.3 & 16.0 & \\
\hline High school & 17.1 & 13.3 & 10.0 & 28.0 & \\
\hline $\begin{array}{l}\text { College and } \\
\text { above }\end{array}$ & 30.0 & 0 & 50.0 & 24.0 & \\
\hline $\begin{array}{l}\text { Annual income } \\
(\mathrm{CNY}), \%\end{array}$ & & & & & 0.093 \\
\hline$<10,000$ & 40.0 & 40.0 & 23.3 & 60.0 & \\
\hline $10,000-59,999$ & 28.6 & 46.7 & 26.7 & 20.0 & \\
\hline $60,000-109,999$ & 24.3 & 13.3 & 36.7 & 16.0 & \\
\hline $110,00-200,000$ & 5.7 & 0.0 & 10.0 & 4.0 & \\
\hline$>200$ thousands & 1.4 & 0.0 & 3.3 & 0.0 & \\
\hline Marriage, \% & & & & & 0.048 \\
\hline Unmarried & 5.7 & 13.3 & 3.3 & 4.0 & \\
\hline Married & 88.6 & 86.7 & 96.7 & 80.0 & \\
\hline Widowed & 5.7 & 0.0 & 0.0 & 16.0 & \\
\hline $\begin{array}{l}\text { Stage of } \\
\text { melanoma, \% }\end{array}$ & & & & & 0.233 \\
\hline
\end{tabular}




\begin{tabular}{|c|c|c|c|c|c|}
\hline \multirow[t]{2}{*}{ Characteristics } & \multirow{2}{*}{$\begin{array}{l}\text { Total } \\
(\mathrm{N}= \\
70)\end{array}$} & \multicolumn{3}{|l|}{ Employment status } & \multirow[t]{2}{*}{$P$} \\
\hline & & $\begin{array}{l}\text { Unemployed } \\
\text { since the } \\
\text { epidemic }(n=15)\end{array}$ & $\begin{array}{l}\text { Unaffected since } \\
\text { the epidemic ( } \\
=30 \text { ) }\end{array}$ & $\begin{array}{l}\text { Unemployed before } \\
\text { the epidemic or retired } \\
(n=25)\end{array}$ & \\
\hline I & 28.6 & 40.0 & 27.0 & 24.0 & \\
\hline II & 32.8 & 7.0 & 40.0 & 40.0 & \\
\hline III & 24.3 & 27.0 & 27.0 & 20.0 & \\
\hline IV & 14.3 & 27.0 & 7.0 & 16.0 & \\
\hline $\begin{array}{l}\text { Course of } \\
\text { melanoma } \\
\text { (year), \% }\end{array}$ & & & & & 0.091 \\
\hline$<1$ & 35.7 & 26.7 & 33.3 & 44.0 & \\
\hline $1-2$ & 51.4 & 40.0 & 56.7 & 52.0 & \\
\hline$\geq 3$ & 12.9 & 33.3 & 10.0 & 4.0 & \\
\hline $\begin{array}{l}\text { Site of } \\
\text { melanoma, \% }\end{array}$ & & & & & 0.987 \\
\hline Extremities & 87.1 & 86.7 & 86.7 & 88.0 & \\
\hline Other sites & 12.9 & 13.3 & 13.3 & 12.0 & \\
\hline $\begin{array}{l}\text { Current status of } \\
\text { melanoma, } \%\end{array}$ & & & & & 0.187 \\
\hline Stable & 72.9 & 60.0 & 86.6 & 64.0 & \\
\hline Recurrent & 14.3 & 26.7 & 6.7 & 16.0 & \\
\hline Metastasis & 12.8 & 13.3 & 6.7 & 20.0 & \\
\hline \multicolumn{6}{|l|}{$\begin{array}{l}\text { History of } \\
\text { disease, \% }\end{array}$} \\
\hline Hypertension & 27.1 & 6.67 & 23.3 & 44.0 & 0.030 \\
\hline Diabetes & 20.0 & 13.3 & 13.3 & 32.0 & 0.174 \\
\hline $\begin{array}{l}\text { Coronary heart } \\
\text { disease }\end{array}$ & 14.3 & 13.3 & 3.3 & 28.0 & 0.034 \\
\hline $\begin{array}{l}\text { Outdoor activity } \\
\text { restriction }\end{array}$ & & & & & 0.160 \\
\hline $\begin{array}{l}\text { Outdoor activity } \\
\text { unrestricted }\end{array}$ & 51.4 & 33.3 & 50.0 & 64.0 & \\
\hline
\end{tabular}




\begin{tabular}{|c|c|c|c|c|c|}
\hline \multirow[t]{2}{*}{ Characteristics } & \multirow{2}{*}{$\begin{array}{l}\text { Total } \\
(\mathrm{N}= \\
70)\end{array}$} & \multicolumn{3}{|c|}{ Employment status } & \multirow[t]{2}{*}{$P$} \\
\hline & & $\begin{array}{l}\text { Unemployed } \\
\text { since the } \\
\text { epidemic }(n=15)\end{array}$ & $\begin{array}{l}\text { Unaffected since } \\
\text { the epidemic ( } \\
=30 \text { ) }\end{array}$ & $\begin{array}{l}\text { Unemployed before } \\
\text { the epidemic or retired } \\
(n=25)\end{array}$ & \\
\hline $\begin{array}{l}\text { Outdoor activity } \\
\text { partly restricted }\end{array}$ & 24.3 & 26.7 & 33.3 & 12.0 & \\
\hline $\begin{array}{l}\text { Isolated at home } \\
\text { or in hospital }\end{array}$ & 24.3 & 40.0 & 16.7 & 24.0 & \\
\hline $\begin{array}{l}\text { Income change } \\
\text { since the } \\
\text { epidemic, \% }\end{array}$ & & & & & 0.003 \\
\hline Complete loss & 15.7 & 26.7 & 10.0 & 16.0 & \\
\hline Reduced & 40.0 & 73.3 & 36.7 & 24.0 & \\
\hline Unaffected & 44.3 & 0.0 & 53.3 & 60.0 & \\
\hline $\begin{array}{l}\text { Unemployment } \\
\text { of family } \\
\text { members, \% }\end{array}$ & & & & & $\begin{array}{l}< \\
0.001\end{array}$ \\
\hline Yes & 32.9 & 80.0 & 20.0 & 20.0 & \\
\hline No & 67.1 & 20.0 & 80.0 & 80.0 & \\
\hline $\begin{array}{l}\text { Adherence to } \\
\text { treatment, \% }\end{array}$ & & & & & 0.748 \\
\hline $\begin{array}{l}\text { No treatment } \\
\text { prescribed }\end{array}$ & 42.9 & 40.0 & 50.0 & 36.0 & \\
\hline $\begin{array}{l}\text { Not adherent to } \\
\text { the treatment }\end{array}$ & 31.4 & 33.3 & 23.3 & 40.0 & \\
\hline $\begin{array}{l}\text { Adherent to the } \\
\text { treatment }\end{array}$ & 25.7 & 26.7 & 26.7 & 24.0 & \\
\hline \multicolumn{6}{|l|}{$\begin{array}{l}\text { Healthcare } \\
\text { utilization }\end{array}$} \\
\hline $\begin{array}{l}\text { Visited a doctor } \\
\text { in hospital, \% }\end{array}$ & 35.7 & 40.0 & 33.3 & 36.0 & 0.907 \\
\hline $\begin{array}{l}\text { Consulted a } \\
\text { doctor remotely, } \\
\%\end{array}$ & 32.9 & 33.3 & 23.3 & 44.0 & 0.267 \\
\hline $\mathrm{SD}^{+}:$Standard & & & & & \\
\hline
\end{tabular}

The distribution of the FACT-G and MS scores by employment status are shown in Fig. 1a, with a clear positive correlation between the two scores. According to the Hotelling's Trace for multivariate test, 
unemployment was significantly associated with the PWB, SWB, and FWB subscale scores, but was not associated with the EWB and MS subscale scores (Fig. 1b). The FACT-G score was the lowest in patients who were unemployed since the epidemic $(P=0.003)$; in contrast, the difference was not significant between the patients who were unaffected and those who were unemployed or retired before the epidemic (Fig. 1C). Income loss and unemployment of family members were also significantly associated with lower FACT-G but not MS score, while adherence to treatment and isolation status were not associated with both outcomes (Fig. 2). It is noteworthy that the patients who reported income loss had a lower proportion of immune therapy at present (9\%) compared to those whose income were unaffected $(17 \%)$.

The stepwise linear regression identified lower educational level, unemployment since the epidemic, and progression of melanoma as risk factors for impaired HRQoL measured as the FACT-G (Table 2). The progression of melanoma and unemployment of family members were significantly associated with the MS score. 
Table 2

Stepwise linear regression for the FACT-G and MS scores

\begin{tabular}{|c|c|c|c|}
\hline Outcomes & Selected factors & Coefficient $\left(\mathrm{SE}^{\dagger}\right)$ & $P$ \\
\hline \multirow[t]{13}{*}{ FACT-G ${ }^{\ddagger}$} & Education & & \\
\hline & Primary school and below & Reference & \\
\hline & Middle school & $4.7(4.9)$ & 0.345 \\
\hline & High school & $11.5(5.4)$ & 0.038 \\
\hline & College and above & $16.7(5.1)$ & 0.002 \\
\hline & Employment status & & \\
\hline & Unemployed since the epidemic & $-10.8(5.2)$ & 0.043 \\
\hline & Unaffected & Reference & \\
\hline & Unemployed before the epidemic or retired & $-0.1(4.5)$ & 0.998 \\
\hline & Current status of melanoma, $\mathrm{n}(\%)$ & & \\
\hline & Stable & Reference & \\
\hline & Recurrent & $-11.9(4.8)$ & 0.016 \\
\hline & Metastasis & $-19.7(5.0)$ & $<0.001$ \\
\hline \multirow[t]{7}{*}{ MS§ } & Current status of melanoma, $\mathrm{n}(\%)$ & & \\
\hline & Stable & Reference & \\
\hline & Recurrent & $-4.5(2.2)$ & 0.038 \\
\hline & Metastasis & $-12.3(2.4)$ & $<0.001$ \\
\hline & Unemployment of family members & & \\
\hline & No & Reference & \\
\hline & Yes & $-5.1(1.7)$ & 0.002 \\
\hline
\end{tabular}

\section{Discussion}

In this study, we investigated the pandemic-related impacts on the HRQoL in melanoma patients through an online survey. The impaired HRQoL of melanoma was associated with the unemployment of the patients and their family members, as well as income loss. These findings provide new insights into the health inequity issue arisen in the particular period. 
It is well established that the health status and psychological characteristics of patients are associated with HRQoL. Previous studies found that patients with melanoma perceived persistent worries about developing new or metastatic cancers [6]. A pervasive sense of uncertainty increases psychological distress, and impairs quality of life [7]. Investigators found that systemic therapies can decrease HRQoL in a short time; however, the long-term HRQoL of melanoma survivors is comparable with the general population $[8,9]$. In the current study, we found that over $20 \%$ of the melanoma patients were unemployed since the epidemic of COVID-19 and their HRQoL were decreased notably. Interestingly, unemployment and a history of melanoma were previously identified to be associated with greater cancer worry, which indicated the importance of both melanoma and unemployment on psychological status [10]. Our findings further emphasize the need to track the mental health of cancer patients under unemployment.

It has been estimated that over 100,000 people will be diagnosed with melanoma this year in the United States according to American Society of Clinical Oncology (ASCO). The incidence rate of melanoma in China was estimated at 0.9 per 100,000 , with a $110.3 \%$ rise compared to the 1990 s [11]. The increasing incidence of melanoma makes it a public health concern and brings the global burden of disease [12]. The disability-adjusted life-years (DALYs) of melanoma have been increasing in China during the last decade, while the DALYs of common cancers such as esophageal cancer and stomach cancer have decreased significantly [11]. In recent years, the development of immune therapy benefits cancer patients substantially, but also leads to a heavy economic burden for them [13]. A review indicates that higher spending on cancer is consistently associated with lower mortality [14]. In other words, loss of income and work-related benefits experienced by the unemployed may lead to adverse health outcomes [15].

Unemployment of the family members further impairs the social support and financial source, resulting in the unaffordability of the advanced therapies and, the progression of cancer and mental stress. This is supported by our finding that unemployment of family member was an independent risk factor for lower MS score. Additionally, a lower proportion of the use of immune therapy during the epidemic period reported by the melanoma patients with income loss indicates that financial status is an essential consideration in the selection of treatment strategy. These findings indicate that health disparities in cancer could result in a vicious circle. Social setting, incorporating poverty, culture, and social justice were found to play a part in disease outcome [16]. Some poverty-related barriers, such as income, education, and health insurance could influence melanoma outcomes [17]. This makes social justice quite essential to diminish the disparities in melanoma.

\section{Conclusion}

To the best of our knowledge, this is the first empirical study of pandemic-related impacts on the HRQoL of melanoma patients. Our finding indicates that early and timely mental health intervention, telemedicine, and health education are needed for melanoma patients. More importantly, health decisionmakers should consider the reimbursement policy of advanced treatment methods for cancers with high fatality rate. 


\section{Limitations}

There are limitations to our study. First, we conducted an online survey instead of the in-person interview because of the high infectivity of the COVID-19. Therefore, the representativeness of our sample might be limited owing to selection bias. Second, a total of 70 patients participated in the study despite our efforts to recruit as more patients as we could. The sample size is relatively small which may lead to insufficient power of test to identify differences. Third, the exposure and outcome variables were self-reported, and recall bias might be introduced. Last, the survey was conducted among Chinese patients, which may not fully represent melanoma patients beyond China owing to the differences in culture, reimbursement policy, and social system.

\section{Abbreviations}

COVID-19: coronavirus disease-2019; HRQoL:health-related quality of life; FACT-M:Functional Assessment of Cancer Therapy-Melanoma; FACT-G:Functional Assessment of Cancer Therapy-General; PWB:physical well-being; SWB:social/family well-being; EWB:emotional well-being; FWB:functional well-being; MS:melanoma subscale; MSS:melanoma surgery scale; AACR:American Society of Clinical Oncology

\section{Declarations}

Ethics approval and consent to participate: The study was reviewed and approved by the institutional research ethics boards of Xiangya Hospital, Central South University (approval number: 202002024). Electronic informed consent was collected from all participants.

Consent for publication: Electronic informed consent for publication was obtained from all participants.

Availability of data and materials: The datasets generated and analysed during the current study are not publicly available but are available from the corresponding author on reasonable request.

Competing interests: The authors declare that they have no competing interests

Funding: This work was supported by the National Natural Science Foundation of China (62041208, 81974478), the Ministry of Science and Technology of the People's Republic of China (2016YFC0900802), the Emergency Project of Prevention and Control for COVID-19 of Central South University (502701002), and the Department of Science and Technology of Hunan Province (2018SK2086, 2018SK2092).

Authors' contributions: YY. Guo designed and built the online questionnaire, and was a major contributor in writing the manuscript. MX. Shen analysed the patient data, reviewed and edited the writing, and provided the funding. X. Zhang and Y. Xiao re-analysed and validated the patient data. S. Zhao, MZ. Yin, Y. Wang and WB. Bu distributed the questionnaire and recruited melanoma patients. J. Su and X. Chen conceptualized and supervised the study, and provided the funding. 
Acknowledgements: We would like to thank all the melanoma patients who participated in our study for their support and assistance in the online survey. Particularly, we want to express our high regard to all the health practitioners and volunteers for their dedication in the fight against COVID-19.

\section{References}

1. Topalian SL, Hodi FS, Brahmer JR, Gettinger SN, Smith DC, McDermott DF, Powderly JD, Sosman JA, Atkins MB, Leming PD, et al: Five-Year Survival and Correlates Among Patients With Advanced Melanoma, Renal Cell Carcinoma, or Non-Small Cell Lung Cancer Treated With Nivolumab. JAMA Oncol 2019.

2. Miller AJ, Mihm MC. Jr.: Melanoma. N Engl J Med. 2006;355:51-65.

3. Kasparian NA, McLoone JK, Butow PN. Psychological responses and coping strategies among patients with malignant melanoma: a systematic review of the literature. Arch Dermatol. 2009;145:1415-27.

4. Seidler AM, Pennie ML, Veledar E, Culler SD, Chen SC. Economic burden of melanoma in the elderly population: population-based analysis of the Surveillance, Epidemiology, and End Results (SEER)-Medicare data. Arch Dermatol. 2010;146:249-56.

5. Cormier JN, Ross MI, Gershenwald JE, Lee JE, Mansfield PF, Camacho LH, Kim K, Webster K, Cella D, Palmer JL. Prospective assessment of the reliability, validity, and sensitivity to change of the Functional Assessment of Cancer Therapy-Melanoma questionnaire. Cancer. 2008;112:2249-57.

6. McLoone J, Watts K, Menzies S, Meiser B, Butow P, Kasparian N. When the risks are high: psychological adjustment among melanoma survivors at high risk of developing new primary disease. Qual Health Res. 2012;22:1102-13.

7. Johnson Wright L, Afari N, Zautra A. The illness uncertainty concept: a review. Curr Pain Headache Rep. 2009;13:133-8.

8. Heino PJ, Myllari PH, Jahkola TA, Sintonen H, Luoma ML, Rasanen P, Roine RP. Long-Term Quality of Life of Melanoma Survivors Is Comparable to that of the General Population. Anticancer Res. 2019;39:2633-40.

9. Cornish D, Holterhues C, van de Poll-Franse LV, Coebergh JW, Nijsten T. A systematic review of healthrelated quality of life in cutaneous melanoma. Ann Oncol. 2009;20(Suppl 6):vi51-58.

10. Khoshab N, Vaidya TS, Dusza S, Nehal KS, Lee EH. Factors contributing to cancer worry in the skin cancer population. J Am Acad Dermatol 2019.

11. Wu $Y$, Wang $Y$, Wang $L$, Yin $P$, Lin $Y$, Zhou M. Burden of melanoma in China, 1990-2017: Findings from the 2017 global burden of disease study. Int J Cancer 2019.

12. Karimkhani C, Green AC, Nijsten T, Weinstock MA, Dellavalle RP, Naghavi M, Fitzmaurice C. The global burden of melanoma: results from the Global Burden of Disease Study 2015. Br J Dermatol. 2017;177:134-40. 
13. Verma V, Sprave T, Haque W, Simone CB 2nd, Chang JY, Welsh JW, Thomas CR. Jr.: A systematic review of the cost and cost-effectiveness studies of immune checkpoint inhibitors. $\mathrm{J}$ Immunother Cancer. 2018;6:128.

14. Li M, Lakdawalla DN, Goldman DP. Association Between Spending and Outcomes for Patients With Cancer. J Clin Oncol. 2020;38:323-31.

15. Stauder J. Unemployment, unemployment duration, and health: selection or causation? Eur J Health Econ. 2019;20:59-73.

16. Freeman HP, Chu KC. Determinants of cancer disparities: barriers to cancer screening, diagnosis, and treatment. Surg Oncol Clin N Am. 2005;14:655-69, v.

17. Harvey VM, Patel H, Sandhu S, Wallington SF, Hinds G. Social determinants of racial and ethnic disparities in cutaneous melanoma outcomes. Cancer Control. 2014;21:343-9.

\section{Figures}
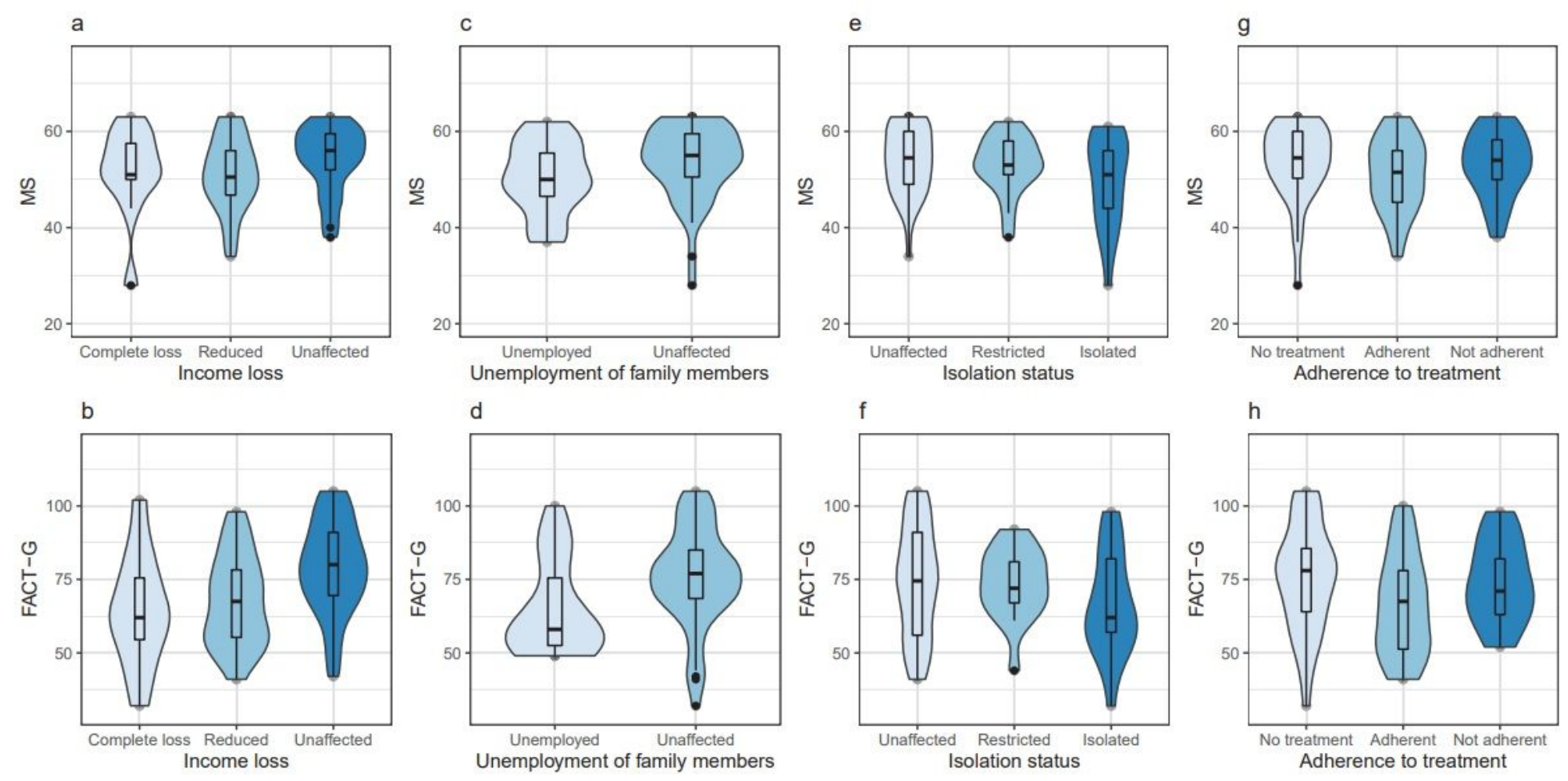

\section{Figure 1}

Violin-boxplot for the distribution of the FACT-G and MS scores by income loss, unemployment of family members, isolation status, and adherence to treatment. 
a

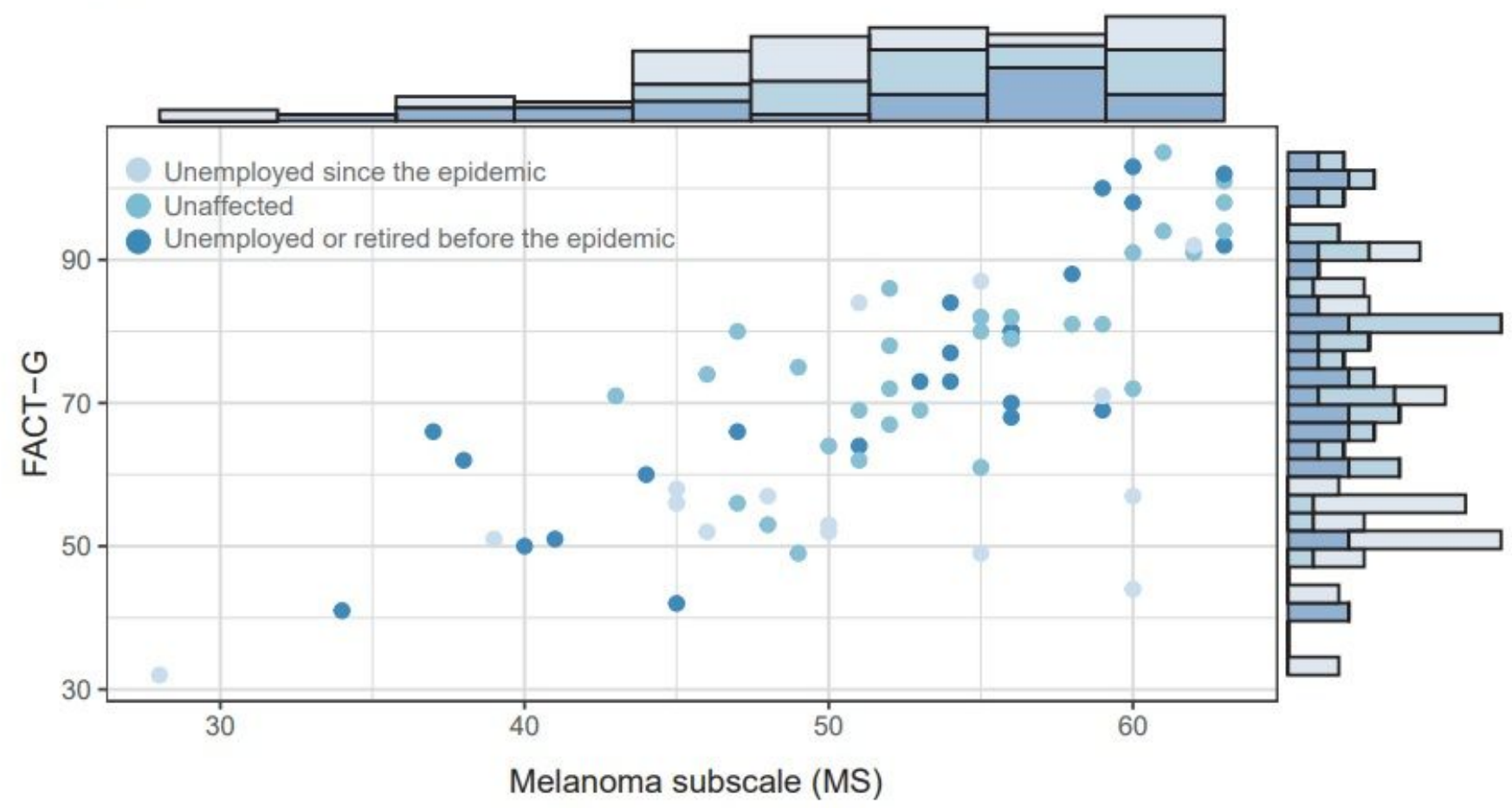

b

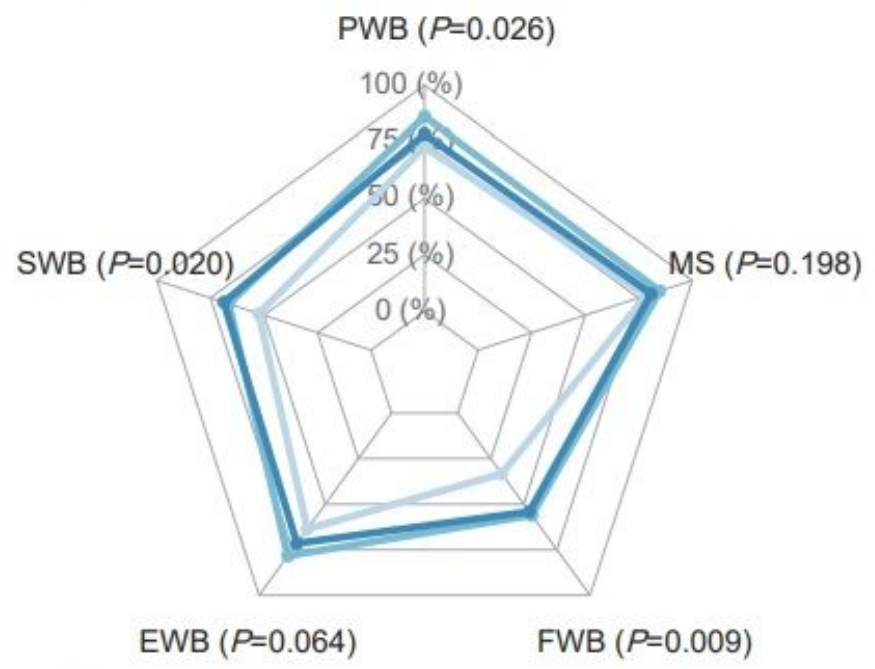

Unemployed since the epidemic

Unaffected

Unemployed or retired before the epidemic

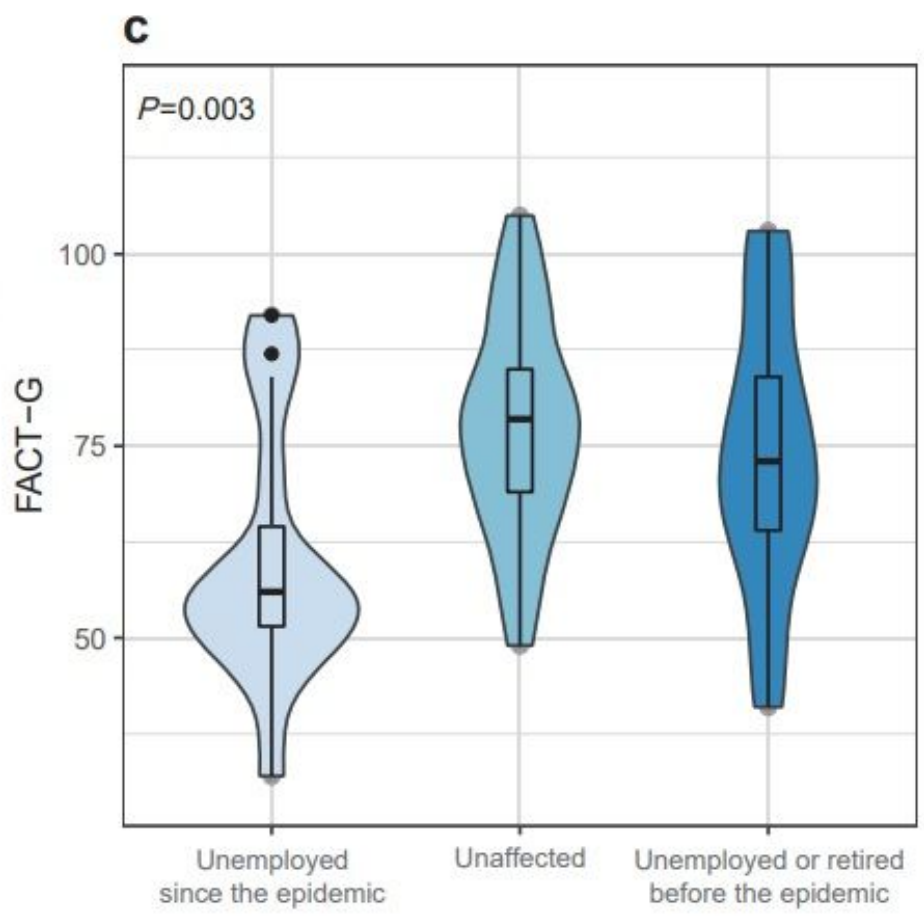

\section{Figure 2}

Association of unemployment with health-related quality of life in melanoma patients. (a) Scatter plot between FACT-G and MS scores by the employment status. (b) Mean subscale scores by the employment status. (c) Violin-boxplot for the distribution of FACT-G and MS scores by the employment status. FACT-G: Functional Assessment of Cancer Therapy-General; MS: melanoma subscale; PWB: physical well-being; SWB: social/family well-being; EWB: emotional well-being; FWB: functional well-being. 